\title{
BMJ Open Quality Long-term improvements following a residential combined physical and psychological programme for chronic low back pain
}

\author{
Shaun Wellburn (D , ${ }^{1}$ Cormac G Ryan, ${ }^{1}$ Andrew Coxon, ${ }^{2}$ Alastair J Dickson, ${ }^{3}$ \\ D John Dickson, ${ }^{3}$ Francis Fatoye ${ }^{4}$ Diarmaid Ferguson, ${ }^{5}$ Paul W Green, ${ }^{2}$ \\ Charles Greenhough, ${ }^{2}$ Sharon Hamilton, ${ }^{1}$ Mary-Anne Jess, ${ }^{6}$ Andrea Jones, ${ }^{7}$ \\ Glynis Peat, ${ }^{2}$ Denis J Martin ${ }^{1}$
}

To cite: Wellburn S, Ryan CG, Coxon A, et al. Long-term improvements following a residential combined physical and psychological programme for chronic low back pain. BMJ Open Quality 2021;10:e001068. doi:10.1136/ bmjoq-2020-001068

Received 17 June 2020 Revised 24 March 2021 Accepted 11 April 2021

D Check for updates

(c) Author(s) (or their employer(s)) 2021. Re-use permitted under CC BY-NC. No commercial re-use. See rights and permissions. Published by BMJ.

${ }^{1}$ School of Health and Life Sciences, Teesside University, Middlesbrough, UK

${ }^{2}$ James Cook University Hospital, Middlesbrough, UK

${ }^{3}$ Primary Care Rheumatology \& Musculoskeletal Medicine Society, Northallerton, UK

${ }^{4}$ Faculty of Health, Psychology and Social Care, Manchester Metropolitan University,

Manchester, UK

${ }^{5}$ Northumbria HealthCare NHS Trust, North Shields, UK

${ }^{6}$ Teesside University,

Middlesbrough, UK

${ }^{7}$ Darlington and Hartlepool and Stockton Clinical Commisioning Group, Darlington, UK

Correspondence to

Dr Shaun Wellburn;

s.wellburn@tees.ac.uk

\section{ABSTRACT}

Objectives Evaluate the outcomes and explore experiences of patients undergoing a residential combined physical and psychological programme (CPPP) for chronic low back pain.

Design A longitudinal observational cohort design, with a parallel qualitative design using semistructured interviews.

Setting Residential, multimodal rehabilitation. Participants 136 adults (62 male/74 female) referred to the CPPP, 100 (44 male/56 female) of whom completed the programme, during the term of the study. Ten ( 2 male/8 female) participated in the qualitative evaluation.

Intervention A 3-week residential CPPP.

Outcome measures Primary outcome measures were the STarT Back screening tool score; pain intensity-11-point Numerical Rating Scale; function-0swestry Disability Index (ODI); health status/quality of life-EQ-5D-5L EuroQol five-Dimension-five level; anxiety-Generalised Anxiety Disorder-7; depression-Patient Health Questionnaire-9. Secondary outcome measures were the Global Subjective Outcome Scale; National Health Service Friends and Family Test;.

Results At discharge, 6 and 12 months follow ups, there were improvements from baseline that were greater than minimum clinically important differences in each of the outcomes (with the sole exception of ODI at discharge). At 12 months, the majority of people considered themselves a lot better (57\%) and were extremely likely $(86 \%)$ to recommend the programme to a friend. The qualitative data showed praise for the residential nature of the intervention and the opportunities for interaction with peers and peer support. There were testimonies of improvements in understanding of pain and how to manage it better. Some participants said they had reduced, or stopped, medication they had been taking to manage their pain.

Conclusions Participants improved, and maintained long term, beyond minimum clinically important differences on a wide range of outcomes. Participants reported an enhanced ability to self-manage their back pain and support for the residential setting.

\section{BACKGROUND}

Low back pain (LBP) is the largest single cause of loss of disability-adjusted life years in the UK at 2313 per 100000 population, ${ }^{1}$ with economic costs rising from $£ 1.6$ billion in $2000^{2}$ to over $£ 2.1$ billion in $2008 .^{3}$ National Institute for Health and Care Excellence (NICE) guidelines bringing together current best evidence, ${ }^{3}$ including the recognition that opioids are not effective in long term LBP, were published to encourage consistent implementation of high quality management of LBP. ${ }^{4}$ The North of England Regional Back Pain and Radicular Pain Pathway operationalises these guidelines and preliminary data indicate that patients on this pathway demonstrate clinically relevant improvements on a range of outcome measures. ${ }^{5}$

For those at high risk of disability, the pathway has an option of an intensive Combined Physical and Psychological Programme (CPPP). The CPPP is a 3-week residential multidisciplinary biopsychosocial rehabilitation intervention that includes physical, psychological and educational components ${ }^{67}$ as recommended by NICE. ${ }^{8}$ A similar residential programme in the Netherlands showed clinically significant improvements in disability and quality of life that persisted into the long term ${ }^{10}$ with mild/moderate disability and being employed included as indicators of successful outcome. ${ }^{11}$

In our study, we aimed to evaluate early and longer-term changes in outcomes in patients referred into the CPPP from the North of England Regional Back Pain and Radicular Pain Pathway; and we aimed to gain insight into understanding the experiences and perceptions of patients referred to the CPPP. 


\section{MATERIALS AND METHODS \\ Design}

This study had two parts. The primary part used a longitudinal observational cohort design to investigate changes in clinical outcomes following the CPPP. The second part was a qualitative design using semi-structured interviews to investigate patients' perceptions of the CPPP.

\section{Public and Patient involvement}

Patients or members of the public were not involved in the design, or conduct, or reporting, or dissemination plans of the research.

\section{Participants}

Participants in the longitudinal cohort study were all of the patients selected to undertake the CPPP during the study period. A subsample took part in the interviews after having provided informed consent to participate in the study. We used purposive sampling to recruit people who had completed the CPPP and people who had been offered a place but had declined this aspect of the pathway. The protocol for this study was registered on a public database (ISRCTN65093728).

\section{Data collection}

For the longitudinal cohort study, baseline questionnaires were completed by participants in the clinic in the presence of their clinicians as part of routine care on the Wednesday introductory session prior to beginning the 3-week programme on the following Monday. The baseline measures were the STarT Back screening tool score $^{12}$; pain intensity-11-point Numerical Rating Scale $(\mathrm{NRS})^{13}$; function-Oswestry Disability Index (ODI $)^{14}$; health status/quality of life-EuroQol five-Dimensionfive level ${ }^{15}$; anxiety-Generalised Anxiety Disorder $(\text { GAD-7 })^{16}$; depression-Patient Health Questionnaire (PHQ-9). ${ }^{17}$ All, apart from STarT Back, were repeated at discharge in the clinic in the presence of the clinicians on the last day of the 3 weeks programme. Follow-up outcome measures were taken at 6 months and 12 months to coincide with planned catch-up days. These were predominantly completed in the clinic in the presence of clinicians. Where people did not attend for whatever reason, they were collected by post or by the clinicians over the phone. (These, like all of the outcomes, were taken as part of clinical practise and then made available to the research team. No record was taken of the exact numbers who completed by post or phone.) Additional measures, taken only at discharge, were the Global Subjective Outcome Scale ${ }^{18}$ and satisfaction with the service they had received-National Health Service (NHS) Friends and Family Test. ${ }^{19}$

For the qualitative study, participants took part in individual semistructured interviews with one of the authors (SW) approximately $6-10$ weeks after completion of the CPPP or, in the case of participants who had declined to take part, $6-10$ weeks after they had declined. The interview was structured to explore what we considered to be key issues and prompts allowed expansion of and from these. The a priori issues of interest were: history of back pain and previous treatment; changes in their back pain and factors they attributed to change; and opinions and experiences of the CPPP content and delivery. The interviews were undertaken in person at a participant's home or workplace, audiorecorded and transcribed verbatim by an external agency.

\section{Data analysis}

For the longitudinal cohort study, change in outcome measures between baseline and discharge; baseline and 6 months follow-up; and baseline and 12 months follow-up were analysed using paired t-tests (IBM SPSS Statistics for Windows, V.23.0, IBM). The magnitude of the change was compared against the minimal clinically important difference (MCID): EQ5D 0.03; NRS 1 point; ODI 10 points; GAD-7 10\%; PHQ-9 10\%. ${ }^{4}$

Framework analysis, assisted by NVivo (QSR International, V.10, 2014), was used with the transcripts of the qualitative interviews. The process followed the steps outlined by Ritchie and Spencer ${ }^{20}$ : familiarisation; identifying a thematic framework; indexing; charting; mapping and interpretation. The basis of the thematic framework was guided by the a priori issues of interest stated above but with freedom to allow for emerging themes.

\section{RESULTS}

\section{Quantitative results}

One hundred and thirty-six patients were invited to take part in the CPPP as part of their routine care, of whom, 100 took part, a $74 \%$ uptake. The list of reasons for not taking part in the CPPP are provided in table 1 .

\begin{tabular}{ll}
\hline Table 1 & Reasons stated for declining referral to CPPP \\
\hline Reason stated & $\begin{array}{l}\text { No of } \\
\text { participants }\end{array}$ \\
\hline Could not be contacted & 8 \\
\hline Did not attend & 6 \\
\hline Work commitments & 6 \\
\hline Child care commitments & 4 \\
\hline Content to self-manage & 2 \\
\hline Family issues & 2 \\
\hline Unable to attend due to physical/ & 2 \\
psychological health issues & 2 \\
\hline Time & 1 \\
Considered it a waste of time & 1 \\
\hline Awaiting emergency scan & 1 \\
\hline Trialling spinal injection with consultant & 1 \\
Out of geographical area and IFR & \\
declined &
\end{tabular}

CPPP, combined physical and psychological programme; IFR, Individual funding request. 
Table 2 Characteristics of people who joined and those who declined the CPPP

\begin{tabular}{llll} 
& Joined $(\mathbf{n}=\mathbf{1 0 0})$ & Declined $(\mathbf{n}=\mathbf{3 6})$ & P value \\
\hline Age (years) & $46.3(12.2)$ & $39.3(11.8)$ & 0.004 \\
Sex (female) & $56.0 \%$ & $50.0 \%$ & 0.537 \\
Socioeconomic status & $5(1-7)$ & $2.5(1-4)$ & 0.012 \\
STarT Back score & $7.4(1.5)$ & $7.1(1.7)$ & 0.422 \\
STarT Back risk (low risk) & $3.0 \%$ & $3.2 \%$ & 0.893 \\
Symptom duration (months) & $120(36-240)$ & $72(24-192)$ & 0.178 \\
\hline
\end{tabular}

Data are mean score (SD), percentage (\%) or median (IQR). Not all participants provided data for each of the variables, the total for each variable is provided. Joined CPPP group: age $(n=100)$, sex $(n=100)$, socioeconomic status $(n=95)$, STarT Back score $(n=73)$, STarT Back risk=dichotomy of scores: low risk=score of $0-3$; score of $>3=$ at risk $(n=73)$, symptom duration $(n=117)$. Declined CPPP group: age ( $n=36)$, sex $(n=36)$, socioeconomic status $(n=34)$, STarT Back score $(n=31)$, STarT Back risk=dichotomy of scores: low risk=score of $0-3$; score of $>3=$ at risk $(n=31)$, Symptom duration $(n=36)$.

CPPP, combined physical and psychological programme.

The baseline characteristics of those who did and did not take part in the CPPP programme are shown in table 2. Compared with those who did attend, those who did not take part were younger and more affluent. Sex and, importantly, STarT Back scores were not found to be statistically significant between the two groups.

Differences between baseline and each of the three post-treatment time points (discharge, 6 and 12 months follow-up) are shown in tables 3-5). At discharge, there were statistically significant improvements in pain, disability, quality of life, anxiety and depression. The improvements in pain, quality of life, anxiety and depression were all greater than the MCID threshold for clinical significance. For disability, the mean improvement of eight points for the ODI was below the MCID of ten points. At 6 and 12 months, the clinically significant improvements in pain, quality of life, anxiety and depression were maintained; and the statistically significant improvement in disability from baseline was now above the MCID. These clinically important improvements persisted at 12 months (and in the outcomes of pain and anxiety the direction of change was in improvements more marked at 12 months). At 12 months, the majority of people considered themselves a lot better $(57 \%)$ and were extremely likely $(86 \%)$ to recommend the programme to a friend (table 6 ).

\section{Qualitative results}

Ten patients were interviewed ( 8 women/2men, age range 35-75). Eight had undertaken the CPPP, while two (both women) had declined. Four themes were described: experiences of back pain; experiences of the CPPP; experiences after participating in the CPPP; recommendations to others.

\section{Experiences of back pain}

The theme describes participants' historical experiences outwith the pathway. Duration of pain ranged from 2 years to over 25 years. All participants reported that their back pain had either remained the same or had worsened over time. Most attributed their back pain to a particular event, lifting, an accident or as a result of an injury or issue with another part of their body. No clear pathway of care could be identified from the discussion with the participants. Typically, participants had been referred to a physiotherapist or a consultant. Expectations at each

\begin{tabular}{lccll}
\hline \multicolumn{2}{l}{ Table 3 Outcome measure changes from baseline to discharge } & & \\
\hline & $\begin{array}{l}\text { Baseline } \\
\text { Mean (SD) }\end{array}$ & $\begin{array}{l}\text { Discharge } \\
\text { Mean (SD) }\end{array}$ & $\begin{array}{l}\text { Mean difference } \\
\text { (95\% Cl) }\end{array}$ & P value \\
\hline Pain NRS $(0-10)^{*}$ & $6.9(1.6)$ & $5.3(1.9)$ & $-1.6(-1.9$, to -1.2$)$ & $<0.001$ \\
\hline ODI $(0-100)^{\star}$ & $47.2(15.2)$ & $39.1(15.6)$ & $-8.1(-9.8$, to -6.4$)$ & $<0.001$ \\
\hline EQ-5D $(1$ to -0.594$) \dagger$ & $0.38(0.24)$ & $0.55(0.21)$ & $0.17(0.13,0.21)$ & $<0.001$ \\
\hline EQ-5D VAS $(0-100) \dagger$ & $49.1(19.8)$ & $62.8(20.2)$ & $13.7(9.9,17.4)$ & $<0.001$ \\
\hline GAD-7 $(0-21)^{*}$ & $10.4(6.3)$ & $6.1(5.0)$ & $-4.4(-5.5$, to -3.2$)$ & $<0.001$ \\
\hline PHQ-9 $(0-27)^{*}$ & $12.8(7.3)$ & $6.8(5.4)$ & $-6.0(-7.3$, to -4.7$)$ & $<0.001$ \\
\hline
\end{tabular}

Not all participants provided data for each of the variables, the total for each variable is provided.

*Higher NRS, ODI, GAD-7 and PHQ-9 scores indicate poorer outcomes.

†Lower EQ-5D and EQ-5D VAS scores indicate poorer outcomes.

EQ-5D, EuroQol five-Dimension Questionnaire ( $n=96)$; GAD-7, Generalised Anxiety Disorder Screener ( $n=92)$; NRS, Numerical Rating Scale $(n=96)$; ODI, Oswestry Disability Index ( $n=95)$; PHQ-9, Patient Health Questionnaire ( $n=89)$; VAS, Visual Analogue Scale ( $n=96)$. 
Table 4 Outcome measure changes from baseline to 6 months

\begin{tabular}{lllll}
\hline Outcome measure & $\begin{array}{l}\text { Baseline } \\
\text { Mean (SD) }\end{array}$ & $\begin{array}{l}\text { Six months } \\
\text { Mean (SD) }\end{array}$ & $\begin{array}{l}\text { Mean difference } \\
\text { (95\% Cl) }\end{array}$ & P value \\
\hline Pain NRS $(0-10)^{*}$ & $6.6(1.8)$ & $4.4(2.2)$ & $-2.2(-2.8$ to -1.6$)$ & $<0.001$ \\
\hline ODI $(0-100)^{\star}$ & $45.7(14.3)$ & $35.5(18.3)$ & $-10.2(-14.1$ to -6.3$)$ & $<0.001$ \\
\hline EQ-5D $(1$ to -0.594$) \dagger$ & $0.36(0.25)$ & $0.56(0.26)$ & $0.21(0.13$ to 0.28$)$ & $<0.001$ \\
\hline EQ-5D VAS $(0-100) \dagger$ & $48.1(19.4)$ & $62.0(23.3)$ & $14.0(7.9$ to 20.1$)$ & $<0.001$ \\
GAD-7 $(0-21)^{\star}$ & $9.7(6.2)$ & $6.3(6.5)$ & $-3.5(-5.2$ to -1.7$)$ & $<0.001$ \\
\hline PHQ-9 $(0-27)^{*}$ & $11.9(7.8)$ & $7.5(6.9)$ & $-4.4(-6.3$ to -2.6$)$ & $<0.001$ \\
\hline
\end{tabular}

Not all participants provided data for each of the variables, the total for each variable is provided.

*Higher NRS, ODI, GAD-7 and PHQ-9 scores indicate poorer outcomes.

†Lower EQ-5D and EQ-5D VAS scores indicate poorer outcomes.

EQ-5D, EuroQol five-Dimension Questionnaire ( $n=51)$; GAD-7, Generalised Anxiety Disorder Screener $(n=49)$; NRS, Numerical Rating Scale ( $n=52)$; ODI, Oswestry Disability Index ( $n=52)$; PHQ-9, Patient Health Questionnaire $(n=48)$; VAS, Visual Analogue Scale $(n=51)$.

point of contact were to relieve the pain and to check for any damage to their spine.

\section{Experiences of the CPPP}

Insights into reasons for not accepting the opportunity to take part in the CPPPP came from two participants. One (CPPP 5) was self-employed and could not afford to take the time off work.

I don't get paid if I'm not at work and that was the one thing. I knew that I couldn't afford to not have that wage. Had there been some sort of funding, then I would have been happy to say to my employer, look I'm going to be on the sick for three weeks, this is why I'm doing it, and I would have done it, gladly. I would have liked to have tried it, had I been able to get some form of sick pay from my company, I would have liked to have gone on it. I think just for the mental side of it more than anything else. (CPPP 5)

This was also a problem for the other participant (CPPP 6 ) coupled with an expectation that it would not address their needs-from the quote this appears to be based on a misconception following an initial consultation. ...it didn't suit me,...I deal a lot with CBT with the kids that I work with and I just felt, I felt a little bit annoyed that I felt like I was being told I didn't really have the pain, that it was all sort of imagined pain. As soon as I came out I knew I didn't want to do the programme. I couldn't...for time constraints with work. (CPPP 6)

Prior expectations formed part of the experience of those who did attend the CPPP. These ranged from being unsure of what to expect but willing to give it a try, to misplaced expectations of becoming totally pain-free.

I was over the moon, because I thought I was going to fixed to be quite honest, I thought I'd come out of there in no pain, or anything. (CPPP 4)

Another participant had their similar expectation tempered by the clear messages given out at the start of the programme that the aims were to understand and manage pain.

To be honest I did think it was going to be a cure. But it was set out so well, and I couldn't speak highly

\begin{tabular}{lllll}
\hline \multicolumn{2}{l}{ Table 5} & Outcome measure changes from baseline to 12 months & & \\
Outcome measure & $\begin{array}{l}\text { Baseline } \\
\text { Mean (SD) }\end{array}$ & $\begin{array}{l}\mathbf{1 2} \text { months } \\
\text { Mean (SD) }\end{array}$ & $\begin{array}{l}\text { Mean difference } \\
\mathbf{( 9 5 \% ~ C l )}\end{array}$ & P value \\
\hline Pain NRS $(0-10)^{\star}$ & $7.1(1.6)$ & $4.2(1.8)$ & $-2.9(-3.5$ to -2.2$)$ & $<0.001$ \\
ODI (0-100) & $51.5(14.5)$ & $36.4(17.7)$ & $-15.1(-20.6$ to -9.7$)$ & $<0.001$ \\
EQ-5D $(1$ to -0.594$) \dagger$ & $0.26(0.22)$ & $0.56(0.22)$ & $0.30(0.21$ to 0.40$)$ & $<0.001$ \\
EQ-5D VAS $(0-100) \dagger$ & $38.2(16.2)$ & $65.4(18.3)$ & $27.2(19.6$ to 34.9$)$ & $<0.001$ \\
GAD-7 $(0-21)^{\star}$ & $12.4(6.4)$ & $5.6(5.2)$ & $-6.7(-9.5$ to -4.0$)$ & $<0.001$ \\
PHQ-9 $(0-27)^{*}$ & $15.2(7.0)$ & $7.4(5.9)$ & $-7.8(-10.8$ to -4.9$)$ & $<0.001$ \\
\hline
\end{tabular}

Not all participants provided data for each of the variables, the total for each variable is provided.

*Higher NRS, ODI, GAD-7 and PHQ-9 scores indicate poorer outcomes.

†Lower EQ-5D and EQ-5D VAS scores indicate poorer outcomes.

EQ-5D, EuroQol five-Dimension Questionnaire ( $n=27)$; GAD-7, Generalised Anxiety Disorder Screener ( $n=26)$; NRS, Numerical Rating Scale $(n=27)$; ODI, Oswestry Disability Index ( $n=27)$; PHQ-9, Patient Health Questionnaire $(n=26)$; VAS, Visual Analogue Scale $(n=27)$. 


\begin{tabular}{|c|c|c|c|}
\hline & Discharge & 6 months & 12 months \\
\hline GSOS & $\mathrm{n}=97, \%$ & $\mathrm{n}=51, \%$ & $\mathrm{n}=28, \%$ \\
\hline Completely better & 0.0 & 2.0 & 3.6 \\
\hline A lot better & 48.5 & 39.2 & 57.1 \\
\hline Moderately better & 28.9 & 27.5 & 21.4 \\
\hline A little better & 0.0 & 11.8 & 7.1 \\
\hline Same & 6.2 & 13.7 & 7.1 \\
\hline Worse & 0 & 5.9 & 3.6 \\
\hline FFT & $\mathrm{n}=97, \%$ & $\mathrm{n}=51, \%$ & $\mathrm{n}=28, \%$ \\
\hline Extremely likely & 84.5 & 78.8 & 85.7 \\
\hline Likely & 15.5 & 17.3 & 14.3 \\
\hline $\begin{array}{l}\text { Neither likely nor } \\
\text { unlikely }\end{array}$ & 0.0 & 1.9 & 0.0 \\
\hline Unlikely & 0.0 & 0.0 & 0.0 \\
\hline Extremely unlikely & 0.0 & 1.9 & 0.0 \\
\hline Don’t know & 0.0 & 0.0 & 0.0 \\
\hline
\end{tabular}

FFT, Friends and Family Test; GSOS, Global Subjective Outcome Scale.

enough of the programme, almost right from day one that this isn't a cure, it's more about understanding pain. (CPPP 8)

Participants who attended the programme were, generally, very positive about it, in some cases describing it as 'brilliant' and 'excellent'. In particular, participants reported that they enjoyed the physical activity aspects of the programme.

...but we'd said that if you had a pool session every morning it just gave you that energy to do the rest of the day because some of some of the days were very, very tiring. (CPPP 3 )

This participant echoed sentiments from others that there could be more of this content.

I would have preferred for it to be more physical activity...I mean [the] hydrotherapy was brilliant. It was very good and the gym, excellent; I even got to jog on a treadmill by the end of it like. (CPPP 1)

One participant reported how the education component of the CPPP helped overcome initial fears of exercise and activity.

So from an exercise point of view, that's given me a lot more confidence knowing that I can do it without, it's not going to cause any flare-ups unless I overdo it, if that makes sense?...the pain management modules were excellent, getting some really good understanding. (CPPP 10)

In general, the pain education sessions were highly praised as helping to better understand the reasons for their pain, alleviating a developed fear of being active, and helping to learn how to manage pain better.

...just the way it was broken down and explained about the pain and the mindfulness and everything. (CPPP 9)

Some participants reported initial anxiety and reticence about the residential nature of the programme. However, having taken part in the programme, participants were positive.

It's necessary I think to stay away because I actually found it hard coming back home on the first Thursday. Yeah, I found it difficult but, yeah, it needs to be residential. (CPPP 3)

The peer support available through being in a groupbased, residential programme was roundly praised

I do think it benefited us all, having a big group of people.... Like I said, being in a group with people who know what you're going through and being able to talk about it. (CPPP 1) and one participant described the residential setting as adding value to the peer support.

It's brilliant, you get cocooned in that little group and you're all trying to help each other and feeding off each other, it was brilliant. (CPPP 2)

Aspects of the programme that were less well received included the sessions on dietary advice. In addition, there were mixed feelings voiced around the mindfulness and meditation sessions on the programme.

Yeah, and the alternative, the alternative things; the meditations and that I'm not a big sort of believer in that sort of thing. (CPPP 2)

I think the stretches and the mindfulness. [aspects of the programme that were particularly good] (CPPP 7)

\section{Experiences after participating in the CPPP}

All participants reported that they had experienced back pain since taking part in the CPPP. There were differing opinions on how they would deal with this pain and whether they would visit their general practitioner (GP) about the pain. Mostly, participants suggested that they felt better able to manage further episodes of back pain through the education and understanding they had obtained by attending the programme.

Yeah, because I know my pain now, I know exactly what the pain is. So I would be able to think oh hang on a minute, that's a bit different. Yeah. I'm dealing with it a lot more effectively, I'm not just taking Tramadol, and just getting on with it. (CPPP 3)

I made this list, and mine was remembering just a little caption that says remember it's only back pain, you can't do anything to break it you know, it's just a flare-up. (CPPP 7) 
Some suggested that they felt able to significantly reduce, or stop taking altogether, the strong pain relief that they had previously been taking for their pain.

I was on the morphine, I just took myself off them because I was having horrendous nightmares... and I thought no, I'm not taking no more of them. So I just stick with the codeine now, I mean they explained how it works and what it does and things like that, and, yeah, I do understand more about my painkillers now. (CPPP 4)

Others stated that they would return to their GP for back pain issues but that it would be more likely for them to return only if there was a specific incident or a change from the back pain they were used to experiencing.

I mean if I've got a lot of pain, I would go and see my GP anyway...so if I had a real flare-up of back pain then yeah I'd go and see my GP. (CPPP 7)

I don't think I would do, because I know there's no magic pill, I know what to do to prevent it. So unless there was something that happened that presented itself in an entirely different way there's no point. (CPPP 8)

\section{Recommendations to others}

Some participants said they had spoken to other people about back pain and that they had promoted the messages they had been given on the programme. They said they had encouraged people not to be afraid of being active and that it was likely to be more beneficial than to do harm.

To not be fearful of exercise and not get out and not try stuff. That it's alright for it to hurt sometimes, but in the long run you're doing yourself better. (CPPP 1)

Also, they suggested that they had told people that the CPPP was excellent and, if they were offered it, they should attend.

\section{DISCUSSION}

We aimed to evaluate the outcomes of patients referred into the CPPP and explore their experiences. The quantitative analysis showed clinically important improvements following the CPPP in pain, quality of life, anxiety and depression that were, at least, sustained over a time period of 12 months. The findings are consistent with the performance of a similar residential programme in the Netherlands ${ }^{910}$ and demonstrate the effectiveness of the CPPP as a mode of operationalising the NICE guidelines in a real-world setting within the context of an integrated care pathway.

Perhaps the most interesting aspects of the qualitative findings were the insights into the value of the residential nature of the intervention. There were many positive comments about the residential requirements including the extra opportunities it offered for interaction with peers and peer support that have been shown to be of benefit in group-based delivery. ${ }^{21-24}$ While most people offered a place on the CPPP took it up, some (26\%) did not. The identification of work commitments as a barrier to participation is important in light of previous work, which showed that being in employment was a factor in successful outcome. ${ }^{11}$ This highlights potential benefits of liaison with occupational health services, an area of need in the provision of musculoskeletal services and pain management services in general. ${ }^{25}$

Most of participants' historical descriptions described a long and frustrating process of seeking a cure. Some reported still having had expectations of a cure at the start of the programme, although they recognised that they were informed that it was about empowering them to live with their pain. Within that context, the CPPP educational component in place to overcome these beliefs, based on the Pain Neuroscience Education programme, ${ }^{26}{ }^{27}$ was highly praised. Participants reported that it helped them to better understand their pain and begin to learn how to manage it better. This knowledge enhancement and understanding is reported in other studies as being similarly important in helping them toward self-management. ${ }^{21-24}$ Attributions of better understanding of pain to an improved ability to manage further episodes are consistent with findings from a 1-year follow-up of a multimodal non-residential programme ${ }^{24}$; this could help to explain the sustained long-term benefits following the CPPP.

The main limitation of the quantitative analysis is the lack of a control group. That was outwith the design of the study and we have been careful to stay away from explicit statements of cause and effect. Nevertheless, the findings are consistent with those studies above that used more controlled experimental designs. The work has been carried out in the North East of England and thus the findings may not be generalisable to other regions. However, the pathway being delivered follows national guidelines and is closely aligned to the UK's national back pain pathway increasing the generalisability of the work. A further limitation of this work was the relatively narrow focus on clinical outcomes with no data about important social impacts. In the case of the qualitative study, the findings are not as comprehensive as would be with a more fully layered purposive sampling strategy with more participants and the findings are illustrative rather than generalisable.

Future work should explore the impact of this and similar programmes in other regions on wider social issues of importance to participants. The environment component of the International Classification of Functioning, Disability and Health provides a useful framework for this. ${ }^{28}$ A key part of the programme is its residential nature and there is an obvious need to compare this with a programme of similar aims and content delivered in non-residential form. An important part of this, and an important area of research on its own, would be to continue to explore the issue of negotiating employment 
commitments with programme access taking account of the gaps between NHS services and occupational health services. $^{25}$

\section{CONCLUSION}

This study found that patients who attended the residential CPPP within the North of England Regional Back Pain and Radicular Pain Pathway improved on a wide range of outcomes by a clinically meaningful amount and these improvements were sustained in the long term (and possibly increased for pain and anxiety). Uptake of the referral to the pathway was high and participants' experiences of the programme were predominantly positive particularly regarding the physical activity and educational components. Participants reported an enhanced ability to self-manage their back pain after undergoing the programme.

Acknowledgements Parts of the results in this paper were previously presented as part of The North of England Regional Back Pain and Radicular Pain Pathway.

Contributors All authors made contributions sufficient to satisfy the criteria for authorship as outlined by the ICMJE.

Funding This work was supported by The Health Foundation (https://www. health.org.uk/), grant number 7416. Academic Health Science Network (https:// www.ahsnnetwork.com/map-region/nenc), grant number ID112. Academic Health Science Network (https://www.ahsnnetwork.com/map-region/nenc), grant number IH21.

Disclaimer The funders had no role in study design, data collection and analysis, decision to publish, or preparation of the manuscript.

Competing interests None declared.

Patient and public involvement Patients and/or the public were not involved in the design, or conduct, or reporting, or dissemination plans of this research.

Patient consent for publication Not required.

Ethics approval This study was approved by the Teesside University Research Ethics and Governance Committee (R179/15; 115/15).

Provenance and peer review Not commissioned; externally peer reviewed.

Data availability statement Data are available on reasonable request. No data are available. Quantitative data used in this study is available from the lead author on request. Ethics clearance was not obtained for public sharing of the transcripts supporting the qualitative analysis in this article.

Open access This is an open access article distributed in accordance with the Creative Commons Attribution Non Commercial (CC BY-NC 4.0) license, which permits others to distribute, remix, adapt, build upon this work non-commercially, and license their derivative works on different terms, provided the original work is properly cited, appropriate credit is given, any changes made indicated, and the use is non-commercial. See: http://creativecommons.org/licenses/by-nc/4.0/.

ORCID iD

Shaun Wellburn http://orcid.org/0000-0003-2630-5876

\section{REFERENCES}

1 Murray CJL, Richards MA, Newton JN, et al. Uk health performance: findings of the global burden of disease study 2010. Lancet 2013;381:997-1020.

2 Maniadakis N, Gray A. The economic burden of back pain in the UK. Pain 2000;84:95-103.

3 Ashworth J, Green DJ, Dunn KM, et al. Opioid use among low back pain patients in primary care: is opioid prescription associated with disability at 6-month follow-up? Pain 2013;154:1038-44.

4 Low back pain: the early management of persistent non-specific low back pain. NICE clinical guideline 88 , guidance.nice.org.uk/cg88 2009.
5 Jess M-A, Ryan C, Hamilton S, et al. Does duration of pain at baseline influence clinical outcomes of low back pain patients managed on an evidence-based pathway? Spine 2018:43:E998-1004.

6 Guzman J, Esmail R, Karjalainen KA. Multidisciplinary bio-psychosocial rehabilitation for chronic low-back pain. Cochrane DB Syst Rev 2006.

7 Smeets RJEM, Vlaeyen JWS, Kester ADM, et al. Reduction of pain catastrophizing mediates the outcome of both physical and cognitive-behavioral treatment in chronic low back pain. $J$ Pain 2006;7:261-71.

8 National Institute for Health and Care Excellence. Low back pain and sciatica in over 16s: assessment and management (NICE guideline NG59). Full guideline, 2016. Available: http://www.nice.org.uk/ guidance/ng59/evidence

9 van Hooff ML, van der Merwe JD, O'Dowd J, et al. Daily functioning and self-management in patients with chronic low back pain after an intensive cognitive behavioral programme for pain management. Eur Spine J 2010;19:1517-26.

10 van Hooff ML, Ter Avest W, Horsting PP, et al. A short, intensive cognitive behavioral pain management program reduces health-care use in patients with chronic low back pain: two-year follow-up results of a prospective cohort. Eur Spine $J$ 2012;21:1257-64.

11 van Hooff ML, van der Merwe JD, O'Dowd J. Daily functioning and self-management in patients with chronic low back pain after an intensive cognitive behavioral programme for pain management. Eur Spine $J$ 2010;19:1517-26.

12 Hill JC, Dunn KM, Lewis M, et al. A primary care back pain screening tool: identifying patient subgroups for initial treatment. Arthritis Rheum 2008;59:632-41.

13 Strong J, Ashton R, Chant D. Pain intensity measurement in chronic low back pain. Clin J Pain 1991;7:209-18.

14 Fairbank JC, Couper J, Davies JB, et al. The Oswestry low back pain disability questionnaire. Physiotherapy 1980;66:271-3.

15 Herdman M, Gudex C, Lloyd A, et al. Development and preliminary testing of the new five-level version of EQ-5D (EQ-5D-5L). Qual Life Res 2011;20:1727-36.

16 Spitzer RL, Kroenke K, Williams JBW, et al. A brief measure for assessing generalized anxiety disorder: the GAD-7. Arch Intern Med 2006;166:1092-7.

17 Kroenke K, Spitzer RL. The PHQ-9: a new depression diagnostic and severity measure. Psychiatr Ann 2002;32:509-15.

18 Harland NJ, Dawkin MJ, Martin D. Relative utility of a visual analogue scale vs. a six-point Likert scale in the measurement of global subject outcome in patients with low back pain receiving physiotherapy. Physiotherapy 2015;101:50-4.

19 NHS England. The friends and family test. NHS England, 2014. Available: https://www.england.nhs.uk/ourwork/pe/fft/ [Accessed 20 Jan 2017].

20 Ritchie J, Spencer L. Qualitative data analysis for applied policy research. In: A B, Burgess RG, eds. Analyzing qualitative data, 1994: 173-94.

21 Pietilä Holmner E, Stålnacke B-M, Enthoven P, et al. "The acceptance" of living with chronic pain - an ongoing process: A qualitative study of patient experiences of multimodal rehabilitation in primary care. $J$ Rehabil Med 2018:50:73-9.

22 Ekhammar A, Melin L, Thorn J, et al. A sense of increased living space after participating in multimodal rehabilitation. Disabil Rehabil 2016;38:2445-54.

23 Hållstam A, Stålnacke BM, Svensen C, et al. "Change is possible": Patients' experience of a multimodal chronic pain rehabilitation programme. J Rehabil Med 2015;47:242-8.

24 Bremander A, Bergman S, Arvidsson B. Perception of multimodal cognitive treatment for people with chronic widespread pain-changing one's life plan. Disabil Rehabil 2009;31:1996-2004.

25 Department of Work and Pensions and Department of Health and Social Care. Understanding the provision of occupational health and work-related musculoskeletal services. DWP/DHSC research document number 985, 2020. Available: https://assets.publishing. service.gov.uk/government/uploads/system/uploads/attachment data/file/887926/RR985-understanding-the-provision-of-OH-andwork-related-MSK-services.pdf

26 Butler DS, Moseley GL. Explain Pain. 2nd edn. Noigroup publications, 2013.

27 Watson JA, Ryan CG, Cooper L, et al. Pain neuroscience education for adults with chronic musculoskeletal pain: a mixed-methods systematic review and meta-analysis. J Pain 2019;20:1140.e1-22.

28 Chapireau $F$. The environment in the International classification of functioning, disability and health. J Appl Res Intellect Disabil 2005;18:305-11. 